\title{
DETERMINANTES DA NECESSIDADE DE CAPITAL DE GIRO E DO CICLO FINANCEIRO DAS EMPRESAS BRASILEIRAS LISTADAS NA B3
}

\author{
DETERMINANTS OF THE WORKING CAPITAL REQUIREMENT AND THE \\ NET OPERATING CYCLE OF BRAZILIAN COMPANIES LISTED IN B3
}

\author{
SABRINA ESPINELE DA SILVA \\ Universidade Federal de Minas Gerais. Endereço: Av. Pres. Antônio Carlos, \\ 6627, Prédio FACE | Pampulha | 31270-901 | Belo Horizonte/MG | Brasil. \\ (1) http://orcid.org/0000-0001-9451-144X \\ sabrinaespinele@gmail.com
}

\author{
MARCOS ANTÔNIO DE CAMARGOS \\ Universidade Federal de Minas Gerais e Faculdade Ibmec de Minas Gerais. \\ Endereço: Av. Pres. Antônio Carlos, 6627, Prédio FACE | Pampulha | 31270- \\ 901 | Belo Horizonte/MG | Brasil. \\ (D) http://orcid.org/0000-0002-3456-8249 \\ marcosac@face.ufmg.br
}

\author{
SIMONE EVANGELISTA FONSECA \\ Universidade Federal de Minas Gerais. Endereço: Av. Pres. Antônio Carlos, \\ 6627, Prédio FACE | Pampulha | 31270-901 | Belo Horizonte/MG | Brasil. \\ Dhttp://orcid.org/0000-0002-1169-8614 \\ simone_fonsecal6@hotmail.com
}

\section{ROBERT ALDO IQUIAPAZA}

Universidade Federal de Minas Gerais. Endereço: Av. Pres. Antônio Carlos, 6627, Prédio FACE | Pampulha | 31270-901 | Belo Horizonte/MG | Brasil. (D) http://orcid.org/0000-0003-1657-2823

rbali@ufmg.br

\section{RESUMO}

A administração financeira de curto prazo é fundamental para a sobrevivência e a lucratividade das empresas. Decisões de ordem operacional podem ter consequências tanto no curto, quanto no longo prazo, afetando o desempenho operacional das empresas. Dessa forma, a gestão eficiente do capital de giro e o conhecimento de seus fatores determinantes são relevantes para os gestores empresariais uma vez que a gestão do capital de giro impacta na liquidez e na rentabilidade das empresas. Este estudo tem por objetivo identificar e analisar os fatores determinantes da necessidade de capital de giro (NCG) e do ciclo financeiro (CF) de empresas não financeiras de capital aberto brasileiras, compreendendo o período de março de 2010 a dezembro de 2016 (28 trimestres). Em termos metodológicos, utilizou-se regressão com dados em painel e o modelo de mínimos quadrados generalizáveis factíveis que é robusto a problemas de heterocedasticidade. Os resultados mostraram que o fluxo de caixa operacional possui uma relação negativa com o ciclo financeiro, enquanto a rentabilidade do ativo e o crescimento das vendas refletiram uma relação 
positiva. Além disso, a liquidez corrente, o tamanho da empresa e a alavancagem se mostraram significantes e negativamente relacionadas à necessidade de capital de giro das empresas.

Palavras-Chave: Administração de Curto Prazo. Necessidade de Capital de Giro. Ciclo Financeiro. Finanças Corporativas.

\begin{abstract}
The working capital management is of great importance for the survival and profitability of the companies. Decisions of operational order can have both short-term and long-term consequences, affecting the operational performance of companies. Thus, the efficient management of working capital and the knowledge of his determinants factors has relevance for business managers since it can impact the liquidity and profitability of companies. The aim of this study was to identify and analyze the determinants of working capital requirement (WCR) and net operating cycle (CF) requirements of Brazilian publicly held non-financial corporations, covering the period from March 2010 to December 2016 (28 quarters). Methodologically, we used regression analysis with panel data and the feasible generalized least squares model that is robust to heteroscedasticity problems. The results showed that the operating cash flow has a negative relation with the net operating cycle, while the asset return and the sales growth have a positive relation. In addition, the current liquidity, the size of the company and the leverage were significant and negatively related to the companies' need for working capital.
\end{abstract}

Keywords: Working capital management. Working capital requirement. Net operating cycle. Corporate Finance.

\title{
1 INTRODUÇÃO
}

O tema abordado nesta pesquisa, gestão do capital de giro, ainda carece de estudos tanto na literatura nacional quanto internacional, dada a sua relevância para a condução dos negócios e por ser determinante do desempenho das empresas (Garcia-Teruel \& Martinez-Solano, 2007). Apesar dos ativos circulantes representarem entre 30 e $40 \%$ do valor do ativo total, sua gestão, entretanto, exige um esforço da área financeira maior do que o requerido pela gestão dos ativos fixos, devido às suas alterações contínuas (Assaf Neto \& Silva, 2009).

Observa-se ao longo da evolução da literatura de finanças corporativas um maior enfoque dado à gestão financeira de longo prazo (Nazir \& Afza, 2009; Palombini \& Nakamura, 2012; Singh \& Kumar, 2014; Chang, 2018). No entanto, a gestão financeira de curto prazo possui importância para as empresas, além de consumir boa parte do tempo e esforço dos gestores financeiros. Em termos acadêmicos ela consiste ainda em um campo pouco explorado nas pesquisas empíricas.

A administração das exigibilidades de curto prazo já representou uma das principais funções financeiras empresariais, pois as empresas preocupavam-se em assegurar a capacidade de pagar suas contas diárias. Porém, o crescimento e desenvolvimento dos mercados acirraram a competição e a abrangência das empresas desviando o foco da administração para uma gestão das aplicações e fontes de recursos da empresa, passando então a ter, uma visão mais ampliada (Fusco, 1996).

Dentro das políticas financeiras de curto prazo as empresas devem gerenciar suas necessidades de capital de giro. $\mathrm{O}$ desempenho futuro de uma empresa pode estar refletido no estudo do capital de giro da mesma, o que torna sua gestão um tema de importância dentro das finanças corporativas (Assaf Neto \& Lima, 2009; Nazir \& Afza, 2009). Para Jalal e Khaksari (2019), o gerenciamento financeiro de curto prazo é uma das três atividades mais importantes dos gestores corporativos, juntamente com o orçamento de capital e o gerenciamento financeiro de longo prazo. 
Assaf Neto e Lima (2009, p. 631) destacam que "[...] todas as decisões financeiras que venham a ser tomadas por uma empresa requerem cuidadosa atenção a seus elementos circulantes". De acordo com Silva, Santos, Hein e Lyra (2012) a boa administração do capital de giro está ligada à liquidez e à solvência empresarial. Além de ser importante para a manutenção da saúde financeira da empresa, a administração do capital de giro também representa uma forma de lidar com as incertezas inerentes aos negócios (Fusco, 1996; Gill, 2011). Seidel e Kume (2003) salientam ainda que a necessidade de capital de giro contribui para que muitas empresas entrem em processo de falência.

Araújo e Machado (2007) argumentam que, o investimento em ativos circulantes representa uma parcela significativa dos investimentos em relação aos ativos totais das empresas. Dessa forma, a administração financeira de curto prazo é importante para a maximização do valor das companhias e do seu desempenho operacional (Chang, 2018). Nazir e Afza (2009) discutem que as empresas podem melhorar o seu desempenho geral, assim como diminuir o seu risco se entenderem o papel e os determinantes do capital de giro. Na mesma linha, Jalal e Khaksari (2019) discutem que existe uma relação entre, o valor de uma empresa, o nível de desenvolvimento de um país e o gerenciamento do capital de giro. Adicionalmente, mostram que firmas com ciclos de caixas mais curtos tendem a ter maior valor de mercado e menor endividamento.

O capital de giro também chamado de capital circulante é definido como os recursos financeiros que giram (circulam) por diversas vezes dentro de um determinado período de tempo. Operacionalmente, ele representa o capital demandado por uma empresa para financiamento do seu ciclo operacional, que envolve desde a necessidade de aquisição de matérias-primas até a venda dos produtos acabados. A importância e o nível desse capital de giro mudam em função das características particulares de cada empresa, bem como do setor de atuação, das condições econômicas e da relação risco e retorno almejada (Fusco,1996; Assaf Neto \& Lima, 2009; Berk \& Demarzo, 2009).

Os componentes do capital de giro são encontrados no circulante da empresa. No passivo circulante são encontradas as origens de recursos de curto prazo. E no ativo circulante encontramse as aplicações de recursos. A diferença entre o total do ativo e do passivo circulante determina o capital de giro líquido da empresa. Uma diferença positiva - quando ativos circulantes superam os passivos circulantes, indica que a empresa tem condições de honrar seus compromissos de curto prazo.

Entretanto certo cuidado deve ser tomado a respeito desse indicador, pois, um valor positivo pode indicar altos níveis de estoques ou muitas duplicatas a receber, ou seja, não está necessariamente indicando que a empresa está em uma situação financeira boa.

Como os fluxos de caixa futuros são permeados de incertezas a gestão do capital de giro torna-se relevante e representa um constante desafio para os gestores. De acordo com Palombini e Nakamura (2012), a realização de uma boa gestão do capital de giro é fundamental para o desempenho operacional das empresas brasileiras, dados os altos custos de realização de empréstimos de curto prazo, além de dificuldades para obtenção de financiamento para as necessidades permanentes de capital de giro.

Estudos internacionais como o de Nazir e Afza (2009), Gill (2011) e Jalal e Khaksari (2019) destacam a importância do gerenciamento eficiente das necessidades de capital de giro. As empresas podem minimizar riscos e melhorar o desempenho de forma geral se conseguirem entender os determinantes da sua necessidade de capital de giro. No entanto, poucos estudos brasileiros exploraram os determinantes das necessidades de capital de giro. É visando preencher essa lacuna na literatura nacional que reside o escopo deste estudo.

Nesse contexto, o objetivo deste estudo é identificar e analisar fatores determinantes da necessidade de capital de giro (NCG) das empresas brasileiras, assim como o seu ciclo financeiro. A NCG é determinada pelo ciclo de caixa da empresa, relaciona-se aos prazos médios de recebimentos e pagamentos e, consequentemente, ao ciclo financeiro. Quando o ciclo é maior a NCG é maior e o contrário também é válido. A previsão da NCG é facilitada pelo cálculo do ciclo 
financeiro em função de uma alteração nas políticas de prazos médios ou no volume de vendas. Esta é a abordagem utilizada neste trabalho.

A análise foi empreendida em uma amostra de 112 empresas de capital aberto e compreende o período entre março de 2010 e dezembro de 2016. Os resultados mostraram que empresas maiores, com maior liquidez corrente e mais alavancadas tendem a ter uma menor necessidade de capital de giro. Enquanto empresas com maiores fluxos de caixa operacional tendem a ter menores ciclos financeiros.

Além desta seção inicial de introdução, este estudo se estrutura da seguinte forma: na segunda seção é apresentada uma revisão da literatura. Na terceira seção são apresentados os procedimentos metodológicos. Na quarta seção são apresentados os resultados e na quinta seção são apresentadas as considerações finais, encerrando-se com as referências consultadas.

\section{REVISÃO DA LITERATURA}

\subsection{Administração Financeira de Curto Prazo e Necessidade de Capital de Giro}

A importância da realização de uma boa gestão empresarial de curto prazo não é tema recente. Smith (1973) já destacava que a falência de algumas empresas poderia ser atribuída à inabilidade dos seus gestores financeiros no planejamento e controle de seus ativos e passivos de curto prazo. Gentry (1988) destaca que a gestão financeira de curto prazo tem um papel fundamental na criação de valor para os acionistas. Nessa mesma perspectiva, Lamberson (1995) salienta ainda que a gestão eficiente das contas de curto prazo demanda tempo e esforço dos administradores empresariais.

O principal objetivo da administração financeira de curto prazo é gerir individualmente os componentes dos ativos circulantes e passivos circulantes com vistas a alcançar um equilíbrio entre rentabilidade e risco, que proporcione aumentos para o valor da empresa. Nessa ótica observa-se a importância de uma boa gestão do capital de giro, que seja capaz de melhorar a posição competitiva da empresa assim como, sua rentabilidade (Gill, 2011). É por essa razão, que nas pesquisas sobre a gestão de capital de giro tem sido amplamente estudado seu impacto sobre a rentabilidade da empresa (Archavli, Siriopoulos \& Arvanitis, 2012).

Nessa direção, estudos da literatura internacional sobre o tema, dentre os quais, os de Shin e Soenen (1998) e Afza e Nazir (2007), destacam que os componentes e a maneira como a empresa gerencia seus recursos de curto prazo (capital de giro) pode ter impacto significativo na sua liquidez, rentabilidade, valor de mercado e criação de valor para os acionistas.

As várias contas que envolvem a análise do capital de giro devem ser administradas de forma a se atingir um equilíbrio: as empresas não devem ter nem pouca nem muita liquidez, e isso proporciona um equilíbrio entre risco e eficiência (Fusco, 1996; Nazir \& Afza, 2009; Gill, 2011). De acordo com Baños-Caballero, García-Teruel e Martínez-Solano (2014, pg.6, tradução nossa) "Existe um nível ótimo de investimento em capital de giro que equilibra os custos e os benefícios desse investimento e maximiza o desempenho empresarial". Deloof (2003) corrobora essa ideia e destaca que as empresas devem ter um nível ótimo de capital de giro de modo a maximizar o seu valor.

Nesse contexto, Eljelly (2004) também discute que uma gestão eficiente do capital de giro tem como ponto central o planejamento e o controle de ativos e passivos circulantes. A ideia é que se invista o mínimo em itens do ativo de modo a minimizar o risco da empresa não ser capaz de honrar suas obrigações futuras. As empresas devem se empenhar para encontrar uma "combinação ótima" de redução dos níveis de estoques e de clientes e aumento dos prazos junto aos seus fornecedores (Kargar \& Blumenthal, 1994). Ganesan (2007) salienta que a gestão eficiente do capital de giro aumenta as oportunidades de crescimento da firma e o retorno dos seus acionistas.

Gill (2011) pontua que para se alcançar um nível ótimo de investimento em capital de giro é necessário um constante monitoramento de seus componentes, como contas a receber, contas a 
pagar, estoques, caixa, entre outros. Além disso, o autor destaca que, a gestão eficiente do capital de giro é de grande importância para as organizações empresariais, pois influencia a liquidez e rentabilidade. Berk e Demarzo (2009, p. 847) destacam que "quaisquer exigências de redução do capital de giro geram um fluxo de caixa livre positivo que a empresa pode distribuir imediatamente aos acionistas".

Seidel e Kume (2003) salientam que a necessidade de capital de giro e suas variações levam muitas empresas à falência. Os autores ponderam que, tão importante quanto as decisões de investimentos em ativos permanentes são as decisões de concessão de prazo a clientes e manutenção de estoques, contas que são contabilizadas no ativo circulante, tendo em vista que essas decisões também possuem efeitos duradouros sobre a saúde financeira da companhia. Deloof (2003) pontua que uma redução no prazo do cliente e dos estoques pode aumentar a rentabilidade da companhia.

As atividades operacionais e financeiras da empresa são preocupações da administração financeira de curto prazo. Essas atividades envolvem desde a compra de matéria-prima, o prazo de pagamento aos fornecedores, a fabricação e a venda do produto assim como a política de crédito que será utilizada. O descasamento entre os prazos de pagamento aos fornecedores e o prazo de recebimento dos clientes representa o ciclo financeiro da empresa, na medida em que o ciclo operacional representa o período de tempo que vai desde a compra da matéria-prima até o efetivo recebimento das vendas realizadas a prazo.

A diferença entre as aplicações e as origens das contas operacionais representa a necessidade de capital de giro (NCG) de uma empresa. Em outras palavras, a diferença entre as contas que compõem o Ativo Circulante Operacional (ACO), como clientes e estoques, e as contas que compõem o Passivo Circulante Operacional (PCO), como fornecedores, fornece o valor da NCG (Seidel \& Kume, 2003). A NCG é uma função do ciclo de caixa da empresa. Quanto maior for o ciclo de caixa maior ela será e vice-versa. Uma das metas da administração financeira é a de receber antecipadamente (redução do prazo de recebimento de clientes) e pagar com o maior prazo possível (aumento do prazo de fornecedores), o que, consequentemente, reduziria o fluxo de caixa e a NCG.

No entanto, para a redução do fluxo de caixa, a empresa deve adotar medidas de ordem operacional, como encurtamento dos prazos de produção, estocagem e vendas. Dessa forma o cálculo da NCG é facilitado pelo cálculo do ciclo financeiro em função de uma alteração no volume de vendas. Seidel e Kume (2003) destacam os diversos motivos que podem provocar mudanças na NCG, entre eles, alteração no preço dos estoques, aumentos ou diminuições no nível de atividade econômica, mudanças nos prazos de pagamento de fornecedores e recebimento de clientes.

Guimarães e Nossa (2010) salientam que a liquidez também é uma variável relacionada ao capital de giro e seu financiamento. A liquidez representa a capacidade da empresa em honrar suas obrigações. A falta de liquidez implica em atrasos no pagamento dos provedores de serviços. De acordo com os autores, a liquidez corrente é o indicador apropriado para verificar a relação entre liquidez e capital de giro já que é o indicador mais comumente utilizado.

\subsection{Estudos Anteriores}

$\mathrm{Na}$ literatura internacional, Chiou, Cheng e Wu (2006) estudaram empresas tailandesas entre 1996 e 2004. Os autores constataram que a alavancagem e o fluxo de caixa operacional afetam de forma negativa o capital de giro e que, o tamanho da empresa tem uma relação positiva com a necessidade de capital de giro.

Nazir e Afza (2009) estudaram os fatores determinantes do capital de giro das empresas não financeiras paquistanesas. Os resultados indicaram uma relação positiva entre o capital de giro, empresas do setor industrial (dummy), o ciclo operacional, o Q de Tobin (desempenho de mercado) e o retorno sobre os ativos. Ademais, apontou uma relação negativa entre o capital de giro e a alavancagem da empresa, demonstrando que empresas com um maior índice de dívida 
sobre ativos totais tendem a prestar mais atenção à gestão eficiente do capital de giro para evitar que parte considerável do capital esteja vinculada às contas a receber e aos estoques. As variáveis, fluxo de caixa operacional, atividade econômica, crescimento das vendas e tamanho não foram estatisticamente significantes.

Hill, Kelly e Highfield (2010) investigaram os fatores que influenciam o investimento líquido no capital de giro operacional (CGO). Os resultados mostraram uma relação negativa e significante entre CGO, crescimento das vendas, volatilidade das vendas, índice valor de mercado sobre valor contábil e índice de dificuldades financeiras. A pesquisa indicou ainda uma relação positiva e significativa entre CGO, fluxo de caixa operacional e tamanho da firma.

O estudo de Gill (2011) teve por objetivo encontrar os fatores que influenciam a demanda de capital de giro de empresas canadenses. Para isso analisou 166 empresas listadas na bolsa de Toronto, por um período de 3 anos 2008-2010. Os resultados mostraram uma relação positiva para o ciclo operacional, retorno sobre os ativos, internacionalização da firma e a dummy para indústria, enquanto uma relação negativa para o crescimento da firma e o tamanho da firma. Relações não significativas foram encontradas para o fluxo de caixa operacional, Q de Tobin e alavancagem.

Wasiuzzaman e Arumugam (2013) investigaram os determinantes do investimento em capital de giro em firmas da Malásia. Os resultados mostraram que, em períodos de expansão econômica, existe uma relação positiva entre o crescimento das vendas, o fluxo de caixa operacional e o investimento em capital de giro. Enquanto essa relação é negativa para a idade da empresa, volatilidade das vendas, tamanho da empresa e o nível de alavancagem.

Baños-Caballero, García-Teruel e Martínez-Solano (2014) focam na relação entre investimento em capital de giro e o desempenho empresarial. Eles analisaram companhias não financeiras do Reino Unido. Os resultados mostraram que existe uma relação invertida em forma de U entre o investimento em capital de giro e o desempenho da empresa. Dessa forma, quando a empresa mantém baixo nível de investimento em capital de giro, a relação entre investimento em capital de giro e desempenho corporativo é positiva. Porém, a relação se inverte para o caso das empresas com alto investimento em capital de giro.

Singh e Kumar (2014) realizaram uma revisão da literatura sobre os estudos de gerenciamento de capital de giro. Os autores concluíram que os estudos dessa área têm direcionado maior atenção à relação entre a gestão de capital de giro e a lucratividade das firmas, ponderando que existe uma lacuna teórica em relação aos estudos desse campo.

Azeem e Marsap (2015) investigaram os fatores determinantes dos requerimentos de capital de giro no Paquistão. Os autores analisaram empresas não financeiras por um período de seis anos. Os resultados mostraram que existe uma relação negativa e estatisticamente significante entre retornos sobre os ativos, alavancagem e tamanho da empresa sobre a demanda de capital de giro. Em contrapartida, o fluxo de caixa operacional apresentou uma relação positiva. Resultados não significativos foram encontrados para o ciclo operacional, nível de atividade econômica e crescimento das vendas.

Na literatura nacional, Palombini e Nakamura (2012) analisaram os fatores determinantes da gestão do capital de giro das empresas brasileiras. Os resultados mostraram que o nível de endividamento, o fluxo de caixa livre, o tamanho da empresa (medido pelo logaritmo das vendas) e o crescimento das vendas têm relação negativa e significativa com o nível de capital de giro das empresas. Esses resultados indicaram que companhias com menor crescimento e menor tamanho investem mais em capital de giro.

Em resumo, as evidências apresentadas na literatura empírica sobre o tema mostram que as variáveis, retornos sobre ativos, nível de alavancagem financeira, fluxo de caixa operacional, crescimento das vendas e tamanho da empresa são relevantes na determinação das necessidades de capital de giro e do ciclo financeiro das companhias. Adicionalmente, uma variável dummy que especifica o setor também se mostra relevante. 
Tabela 1

Resumo dos Principais Estudos sobre o Tema

\begin{tabular}{|c|c|c|c|}
\hline Autor & Período & País & Resultados \\
\hline Chiou, Cheng e Wu (2006) & $1996-2004$ & Tailândia & $\begin{array}{l}\text { Constataram que a alavancagem e o fluxo de } \\
\text { caixa operacional afetam de forma negativa o } \\
\text { capital de giro e que, o tamanho da empresa } \\
\text { tem uma relação positiva com a necessidade } \\
\text { de capital de giro }\end{array}$ \\
\hline Nazir e Afza (2009) & $2004-2007$ & Paquistão & $\begin{array}{l}\text { Constataram uma relação positiva entre o } \\
\text { capital de giro, empresas do setor industrial } \\
\text { (dummy), o ciclo operacional, o Q de Tobin } \\
\text { (desempenho de mercado) e o retorno sobre } \\
\text { os ativos. Ademais, apontou uma relação } \\
\text { negativa entre o capital de giro e a } \\
\text { alavancagem da empresa. }\end{array}$ \\
\hline $\begin{array}{l}\text { Hill, Kelly e Highfield } \\
\text { (2010) }\end{array}$ & $1991-2006$ & Estados Unidos & $\begin{array}{l}\text { Constataram uma relação negativa e } \\
\text { significante entre capital de giro operacional } \\
\text { (CGO), crescimento das vendas, volatilidade } \\
\text { das vendas, índice valor de mercado sobre } \\
\text { valor contábil e índice de dificuldades } \\
\text { financeiras. A pesquisa indicou ainda uma } \\
\text { relação positiva e significativa entre CGO, } \\
\text { fluxo de caixa operacional e tamanho da } \\
\text { firma. }\end{array}$ \\
\hline Gill (2011) & $2008-2010$ & Canadá & $\begin{array}{l}\text { Constatou uma relação positiva para o ciclo } \\
\text { operacional, retorno sobre os ativos, } \\
\text { internacionalização da firma e a dummy para } \\
\text { indústria, enquanto uma relação negativa para } \\
\text { o crescimento da firma e o tamanho da firma. } \\
\text { Relações não significativas foram } \\
\text { encontradas quanto ao fluxo de caixa } \\
\text { operacional, Q de Tobin e alavancagem. }\end{array}$ \\
\hline $\begin{array}{l}\text { Palombini e Nakamura } \\
\text { (2012) }\end{array}$ & $2001-2008$ & Brasil & $\begin{array}{l}\text { Constataram que o nível de endividamento, o } \\
\text { fluxo de caixa livre, o tamanho da empresa } \\
\text { (medido pelo logaritmo das vendas) e o } \\
\text { crescimento das vendas têm relação negativa } \\
\text { e significativa com o nível de capital de giro } \\
\text { das empresas. }\end{array}$ \\
\hline $\begin{array}{l}\text { Wasiuzzaman e Arumugam } \\
\qquad(2013)\end{array}$ & $2000-2007$ & Malásia & $\begin{array}{l}\text { Constataram que, em períodos de expansão } \\
\text { econômica, existe uma relação positiva entre } \\
\text { o crescimento das vendas, o fluxo de caixa } \\
\text { operacional e o investimento em capital de } \\
\text { giro. Enquanto essa relação é negativa para a } \\
\text { idade da empresa, volatilidade das vendas, } \\
\text { tamanho da empresa e o nível de } \\
\text { alavancagem. }\end{array}$ \\
\hline $\begin{array}{l}\text { Baños-Caballero, García- } \\
\text { Teruel e Martínez-Solano } \\
\qquad(2014)\end{array}$ & $2001-2007$ & Reino Unido & $\begin{array}{l}\text { Constataram que existe uma relação invertida } \\
\text { em forma de U entre o investimento em } \\
\text { capital de giro e o desempenho da empresa. } \\
\text { Dessa forma, quando a empresa mantém } \\
\text { baixo nível de investimento em capital de } \\
\text { giro, a relação entre investimento em capital } \\
\text { de giro e desempenho corporativo é positiva. } \\
\text { Porém a relação se inverte para o caso das } \\
\text { empresas com alto investimento em capital de } \\
\text { giro. }\end{array}$ \\
\hline Azeem e Marsap (2015) & $2004-2009$ & Paquistão & $\begin{array}{l}\text { Constataram que existe uma relação negativa } \\
\text { e estatisticamente significante entre retornos } \\
\text { sobre os ativos, alavancagem e tamanho da }\end{array}$ \\
\hline
\end{tabular}




\begin{tabular}{l|l|l}
\hline & & $\begin{array}{l}\text { empresa sobre a demanda de capital de giro. } \\
\text { Em contrapartida, o fluxo de caixa } \\
\text { operacional apresentou uma relação positiva. } \\
\text { Resultados não significativos foram } \\
\text { encontrados para o ciclo operacional, nível de } \\
\text { atividade econômica e crescimento das } \\
\text { vendas. }\end{array}$ \\
\hline
\end{tabular}

Fonte: Elaborado pelos autores.

\section{METODOLOGIA}

A análise de fatores determinantes da necessidade de capital de giro (NCG) e do ciclo financeiro das empresas brasileiras de capital aberto foi realizada por pesquisa de abordagem quantitativa de dados, utilizando-se de regressão com dados em painel. No que tange aos objetivos, trata-se de uma pesquisa do tipo descritiva, ex-post-facto e com a utilização de dados secundários.

\subsection{Dados e Amostra}

Os dados utilizados foram coletados na base Quantum Axis e compreendem informações financeiras de todas as empresas de capital aberto disponíveis na B3 (Brasil, Bolsa e Balcão). Salienta-se que as empresas do setor financeiro foram excluídas da amostra devido às especificidades e padronização dos seus demonstrativos financeiros.

O período analisado foi de março de 2010 a dezembro de 2016. A justificativa de escolha desse período se deve ao fato da implantação dos padrões internacionais de Contabilidade (normas IFRS- International Financial Reporting Standards) em 2010. A utilização de dados anteriores a essa implantação poderia enviesar os resultados. Foram coletadas informações trimestrais relativas ao ciclo financeiro, liquidez corrente, lucro/prejuízo do período, receita líquida, ativo total, alavancagem (dívida bruta sobre ativo total), fluxo de caixa líquido das atividades operacionais e patrimônio líquido (PL) das empresas.

Como forma de tornar os resultados das estimações mais robustos foram excluídas da amostra, informações de empresas com PL negativo, dados financeiros faltantes, valores de vendas negativos e ativos totais não positivos, procedimento semelhante ao realizado por Hill, Kelly e Highfield (2010). Ademais, empresas que apresentavam informações extremas em relação às demais também foram excluídas da amostra com vistas a evitar problemas provenientes de outliers na estimação, procedimento semelhante ao realizado por Palombini e Nakamura (2012).

Diante disso, a amostra final foi constituída de 112 empresas não financeiras de capital aberto, que atuam em nove setores do mercado. No total foram consideradas 2.997 observações trimestrais.

\subsection{Variáveis e Modelo Econométrico}

A necessidade de capital de giro (NCG) das empresas foi calculada por meio do ciclo financeiro e das vendas diárias. Como os dados de vendas foram coletados em periodicidade trimestral, eles foram divididos por 90 (3 meses x 30 dias) com o objetivo de transformá-los em dados diários. A NCG foi calculada, portanto, de acordo com a Equação 1.

$$
\boldsymbol{N C G _ { t }}=\text { Ciclo_Financeiro }_{t} x \frac{\text { Vendas_Trimestrais }}{90} \quad \text { Equação (1) }
$$

Com o objetivo de controlar o efeito do tamanho das empresas a NCG foi calculada em termos relativos ao ativo total, ou seja, a NCG de cada empresa em cada trimestre foi dividida pelo respectivo valor do ativo total no trimestre anterior, procedimento semelhante ao adotado por Nazir e Afza (2009). 
A proxy para o tamanho da empresa se constituiu do logaritmo natural (LN) da receita líquida, assim como proposto por Palombini e Nakamura (2012). Alternativamente, o tamanho também foi medido pelo LN dos ativos totais assim como procedido por Gill (2011) e Azeem e Marsap (2015). A escolha de duas medidas se deu, pois, a primeira medida de tamanho não seria adequada para a equação que tem como variável dependente a NCG. Dessa forma, as variáveis dependentes que representam o tamanho (TAM e TAM (2)) foram calculadas conforme as Equações 2 e 3.

$$
\begin{array}{cr}
\text { Tamanho }=\ln (\text { Receita_Liquida }) & \text { Equação (2) } \\
\text { Tamanho_2 }=\ln (\text { Ativos_Totais }) & \text { Equação (3) }
\end{array}
$$

A medida de alavancagem financeira foi calculada pela divisão da dívida bruta da empresa em cada trimestre pelos ativos totais no mesmo período. O cálculo da alavancagem (ALAV) empresarial foi realizado de acordo com a equação 4.

$$
\text { Alavancagem }=\frac{\text { Divida_Bruta }}{\text { Ativos_Totais }} \quad \text { Equação (4) }
$$

O crescimento das vendas (CRESC) foi calculado por meio da diferenciação da série, ou seja, as vendas no período t subtraídas das vendas no período t-1. Esse procedimento pode ser observado na equação 5 .

$$
\text { Crescimento }=\text { Vendas }_{t}-\text { Vendas }_{t-1} \quad \text { Equação (5) }
$$

Com vistas a captar a diferença da NCG nos diferentes segmentos de mercado, uma variável dummy foi incluída na regressão de forma a diferenciar as empresas do segmento industrial. As demais variáveis: liquidez corrente (LC) e fluxo de caixa operacional líquido (FCO), foram obtidas diretamente da base de dados.

Dessa forma, foram estimados dois modelos de regressão múltipla com dados em painel, visto que os dados são compostos por várias empresas ao longo de um período temporal, ou seja, há variações entre as unidades e variações no tempo. Os modelos foram estimados de acordo com as equações 6 e 7 .

$$
\begin{gathered}
C F_{i, t}=F C O_{i, t-1}+R O A_{i, t-1}+L C_{i, t-1}+T A M_{i, t-1}+A L A V_{i, t-1}+C R E S C_{i, t}+I N D+\varepsilon_{i, t} \\
\text { Equação (6) } \\
N C G_{i, t}=F C O_{i, t-1}+R O A_{i, t-1}+L C_{i, t-1}+T A M(2)_{i, t-1}+A L A V_{i, t-1}+C R E S C_{i, t}+I N D+\varepsilon_{i, t} \\
\text { Equação (7) }
\end{gathered}
$$

Em que: CF representa o ciclo financeiro das empresas, NCG representa a necessidade de capital de giro ponderada pelo ativo total, FCO representa o fluxo de caixa operacional ponderado pelo ativo total, ROA representa a rentabilidade do ativo, LC representa a liquidez corrente, TAM representa o logaritmo natural das receitas líquidas, TAM(2) representa o logaritmo natural do ativo total, ALAV representa a dívida bruta ponderada pelo ativo total, CRESC representa a variação das vendas, todas as variáveis em relação à empresa i no período t-1 ou t. IND é uma dummy que assume valor 1 para empresas do setor industrial e, 0 para empresas do setor comercial e de serviços.

Para validar o modelo econométrico proposto foram realizados testes de multicolinearidade (VIF), normalidade (Shapiro-Wilk) e homoscedasticidade (Breusch-Pagan). O teste de Hausman 
também foi realizado para verificar a adequabilidade entre um modelo para dados em painel com efeitos fixos x efeitos aleatórios.

No entanto, em razão dos testes de heterocedasticidade terem apontado para a rejeição da hipótese nula, ou seja, apontaram problemas de heterocedasticidade nos dados, os modelos das equações 6 e 7 foram estimados também pelo método dos mínimos quadrados generalizados factíveis, visto que este método é robusto a problemas de heterocedasticidade. A Tabela 2 apresenta um resumo das variáveis utilizadas, a sua respectiva operacionalização assim como sua fonte teórica/empírica.

Tabela 2

Operacionalização das variáveis do modelo proposto

\begin{tabular}{|c|c|c|c|c|}
\hline \multicolumn{5}{|c|}{ Variáveis Dependentes } \\
\hline $\mathbf{N}^{\circ}$ & Variável & Sigla & Cálculo & Fonte Teórica \\
\hline 1 & $\begin{array}{c}\text { Fluxo de Caixa } \\
\text { Operacional }\end{array}$ & $\mathrm{FCO}$ & $\begin{array}{l}\text { Caixa Líquido Atividades } \\
\text { Operacionais / Ativo Total }\end{array}$ & Wasiuzzaman e Arumugam (2013) \\
\hline 2 & $\begin{array}{c}\text { Rentabilidade do } \\
\text { Ativo }\end{array}$ & ROA & Lucro Líquido / Ativo Total & $\begin{array}{l}\text { Nazir e Afza (2009); Azeem e } \\
\text { Marsap (2015) }\end{array}$ \\
\hline 3 & Liquidez Corrente & $\mathrm{LC}$ & $\begin{array}{c}\text { Ativo Circulante / Passivo } \\
\text { Circulante }\end{array}$ & Guimarães e Nossa (2010) \\
\hline 4 & Tamanho & TAM & ln (Receita Líquida) & Palombini e Nakamura (2012) \\
\hline 5 & Tamanho & TAM (2) & $\ln$ (Ativo Total) & Nazir e Afza (2009); Gill (2011) \\
\hline 6 & Alavancagem & ALAV & Dívida Bruta / Ativo Total & $\begin{array}{l}\text { Palombini e Nakamura (2012); } \\
\text { Wasiuzzaman e Arumugam (2013); } \\
\text { Azeem e Marsap (2015) }\end{array}$ \\
\hline 7 & $\begin{array}{l}\text { Crescimento das } \\
\text { Vendas }\end{array}$ & CRESC & Vendas $(\mathrm{t})-$ Vendas $(\mathrm{t}-1)$ & $\begin{array}{l}\text { Palombini e Nakamura (2012); } \\
\text { Wasiuzzaman e Arumugam (2013) }\end{array}$ \\
\hline 8 & $\begin{array}{l}\text { Segmento de } \\
\text { Indústria }\end{array}$ & IND & $\begin{array}{l}\text { Dummy para segmento de } \\
\text { indústria }\end{array}$ & Nazir e Afza (2009); Gill (2011) \\
\hline
\end{tabular}

Fonte: Elaborado pelos autores.

\section{RESULTADOS}

\subsection{Estatísticas Descritivas das Variáveis}

A Tabela 3 apresenta as estatísticas descritivas das variáveis utilizadas no modelo de regressão. Como esperado, observou-se valores heterogêneos, tendo em vista a diversidade das empresas analisadas, diferentes características e setores da economia. O coeficiente de variação, razão entre desvio e média das variáveis, ressalta a heterogenia das empresas, principalmente em relação a CF, NCG, ROA e CRESC das empresas.

Tabela 3

Estatísticas descritivas das variáveis

\begin{tabular}{c|c|c|c|c|c|c|c|c|c}
\hline & CF & NCG & FCO & ROA & LC & TAM & TAM(2) & ALAV & CRES \\
\hline Unid. & Dias & \$/AT & \$/AT & \% & & In(RL) & $\ln (\mathbf{A T})$ & \$/AT & \$/AT \\
\hline $\mathbf{N}^{\circ}$ Obs. & 2.997 & 2.997 & 2.997 & 2.997 & 2.997 & 2.997 & 2.997 & 2.997 & 2.997 \\
\hline $\mathbf{N}^{\circ}$ Emp. & 112 & 112 & 112 & 112 & 112 & 112 & 112 & 112 & 112 \\
\hline Mínimo & $-259,4$ & $-7,72$ & $-0,16$ & $-16,29$ & 0,4 & 9,24 & 11,79 & 0 & $-2,69$ \\
\hline Máximo & 309,4 & 24,61 & 0,56 & 32,85 & 7,87 & 19,64 & 20,65 & 0,75 & 68,71 \\
\hline $\mathbf{1}^{\circ} \mathbf{Q}$. & 17,1 & 0,09 & 0,07 & 1,51 & 1,13 & 14 & 14,45 & 0,22 & $-0,02$ \\
\hline
\end{tabular}




\begin{tabular}{c|c|c|c|c|c|c|c|c|c}
\hline $\mathbf{3}^{\circ} \mathbf{Q}$. & 107,3 & 0,99 & 0,16 & 7,61 & 2,06 & 15,8 & 16,41 & 0,42 & 0,13 \\
\hline Média & 66,75 & 0,61 & 0,12 & 4,54 & 1,7 & 14,95 & 15,41 & 0,32 & 0,12 \\
\hline Mediana & 52,3 & 0,33 & 0,12 & 4,39 & 1,55 & 14,95 & 15,37 & 0,32 & 0,04 \\
\hline DP & 71,32 & 1,02 & 0,08 & 5,06 & 0,83 & 1,47 & 1,49 & 0,14 & 1,76 \\
\hline $\mathbf{C V}$ & 1,07 & 1,67 & 0,67 & 1,11 & 0,49 & 0,10 & 0,10 & 0,44 & 14,67 \\
\hline
\end{tabular}

Fonte: Elaborada pelos autores.

As estatísticas mostram que as empresas apresentaram em média e mediana uma necessidade de capital de giro positiva, demonstrando que, em geral, as empresas possuem um ciclo de caixa longo, ou seja, ainda precisam trabalhar na gestão dos seus prazos operacionais (de estocagem, recebimento e pagamento), com vistas a tentar reduzir o ciclo de caixa, adotando medidas de natureza operacional, como encurtamento dos prazos concedidos a clientes e adiantamento dos prazos de pagamento a fornecedores.

Sendo observado também, que as empresas possuem em média um ciclo financeiro positivo demonstrando que o ciclo econômico e o ciclo operacional das empresas brasileiras de forma geral tendem a ser maiores do que o prazo médio de pagamento a fornecedores. As empresas também apresentam, em média, baixo nível de alavancagem (32\%) e crescimento médio de $12 \%$ nas vendas no período analisado.

\subsection{Resultados das Estimações}

Na Tabela 4, podem ser observados os resultados do modelo de regressão para dados em painel, tendo como variável dependente o ciclo financeiro das empresas. Optou-se por apresentar o resultado dos três modelos (pooling, efeitos fixos e efeitos aleatórios).

Tabela 4

Resultado do Modelo para Dados em Painel (Ciclo Financeiro)

\begin{tabular}{|c|c|c|c|}
\hline & \multicolumn{3}{|c|}{ Ciclo Financeiro } \\
\hline & Pooling & Efeitos Fixos & Efeitos Aleatórios \\
\hline \multirow[t]{2}{*}{$\mathrm{FCO}$} & $-93.077 * * *$ & $49.823 * * *$ & $44.871 * * *$ \\
\hline & (17.567) & (13.574) & (13.574) \\
\hline \multirow[t]{2}{*}{ ROA } & $-1.161 * * *$ & $0.324 *$ & 0.283 \\
\hline & $(0.270)$ & $(0.179)$ & $(0.180)$ \\
\hline \multirow[t]{2}{*}{$\mathrm{LC}$} & $29.124 * * *$ & -0.327 & 0.431 \\
\hline & $(1.367)$ & $(1.021)$ & $(1.022)$ \\
\hline \multirow[t]{2}{*}{ TAM } & $-14.037 * * *$ & $-6.374 * * *$ & $-8.349 * * *$ \\
\hline & $(0.794)$ & $(1.585)$ & $(1.453)$ \\
\hline \multirow[t]{2}{*}{ ALAV } & $-19.771 * *$ & 9.007 & 7.328 \\
\hline & $(8.390)$ & $(8.011)$ & (7.948) \\
\hline \multirow[t]{2}{*}{ CRES } & -0.195 & 0.326 & 0.300 \\
\hline & $(0.636)$ & $(0.302)$ & $(0.306)$ \\
\hline \multirow[t]{2}{*}{ IND } & $4.730^{*}$ & & -0.242 \\
\hline & $(2.849)$ & & $(12.093)$ \\
\hline \multirow[t]{2}{*}{ Constant } & $248.629 * * *$ & & $181.980 * * *$ \\
\hline & $(12.309)$ & & $(22.650)$ \\
\hline $\mathrm{R}^{2}$ & 0.27 & 0.016 & 0.019 \\
\hline F-Statistic & $157.976^{* * *}$ & $7.789 * * *$ & $8.247 * * *$ \\
\hline
\end{tabular}

Nota. valores entre parênteses representam o erro padrão das variáveis; *, **, *** significância a 5\%; $1 \%$ e $0,1 \%$, respectivamente. Fonte: Elaborada pelos autores. 
Dos resultados do modelo, expostos na Tabela 4, conclui-se que o fluxo de caixa operacional e o tamanho da empresa possuem relação estatisticamente significante com o ciclo financeiro, com empresas maiores apresentando ciclos financeiros menores. Entretanto, antes da realização de inferências, procedeu-se aos testes de validação do modelo, que podem ser observados na Tabela 53.

Os resultados do teste VIF (Tabela 5) retornou valores inferiores a 2, apontando assim, para a ausência de multicolinearidade entre as variáveis explicativas do modelo proposto. O teste de normalidade dos termos de distribuição dos resíduos de Shapiro-Wilk, levou a rejeição da hipótese nula de normalidade, levando assim à conclusão de que os termos de erro do modelo não são normalmente distribuídos. O teste de Breush-Pagan também levou à rejeição da hipótese nula de homoscedasticidade dos termos de erro, ou seja, os dados apresentam heterocedasticidade. Já o teste de Hausman aponta para a rejeição da hipótese nula, apontando para a adequação da utilização de um modelo de efeitos fixos.

Tabela 5

\section{Resultados dos Testes de Validação}

\begin{tabular}{l|ll}
\hline Teste & Estatística & p-valor \\
\hline VIF (maior valor) & 1.5049 & - \\
Shapiro-Wilk & 0.83089 & $0.0000^{*}$ \\
Breush-Pagan & 995.65 & $0.0000^{*}$ \\
Hausman - Test & 17.256 & $0.0083^{*}$ \\
\hline
\end{tabular}

Nota. *,**,*** significância a $5 \%, 1 \%$ e $<0,1 \%$, respectivamente.

Fonte: Elaborada pelos autores.

Devido aos resultados dos testes de validação do modelo, procedeu-se à aplicação de um modelo de regressão robusto à presença de heterocedasticidade. Assim, estimou-se o modelo da equação 6 pelo método de mínimos quadrados generalizados factíveis com efeitos fixos. Os resultados dessa estimação são apresentados mais adiante na Tabela 8. Porém, antes da aplicação de um modelo robusto verificam-se os resultados para o modelo de dados em painel para a equação 7, que podem ser observados na Tabela 6 .

Tabela 6

\section{Resultado do Modelo para Dados em Painel (NCG)}

\begin{tabular}{cccc}
\hline & \multicolumn{3}{c}{ NCG } \\
\hline & Pooling & $\begin{array}{c}\text { Efeitos } \\
\text { Fixos }\end{array}$ & Efeitos Aleatórios \\
\hline FCO & $-0.568^{* *}$ & $0.830^{* * *}$ & $0.674^{* *}$ \\
& $(0.233)$ & $(0.280)$ & $(0.272)$ \\
\hline ROA & 0.002 & $0.006^{*}$ & $0.006^{*}$ \\
& $(0.004)$ & $(0.004)$ & $(0.004)$ \\
\hline LC & $0.241^{* * *}$ & -0.008 & 0.015 \\
& $(0.018)$ & $(0.021)$ & $(0.021)$ \\
\hline TAM $(2)$ & $-0.094^{* * *}$ & $0.066^{* *}$ & -0.011 \\
& $(0.011)$ & $(0.033)$ & $(0.025)$ \\
\hline ALAV & $-0.515^{* * *}$ & $-1.132^{* * *}$ & $-1.042^{* * *}$ \\
& $(0.111)$ & $(0.165)$ & $(0.156)$ \\
\hline CRES & $0.323^{* * *}$ & $0.324^{* * *}$ & $0.323^{* * *}$ \\
& $(0.008)$ & $(0.006)$ & $(0.006)$ \\
\hline IND & $0.096^{* *}$ & & 0.110 \\
& $(0.038)$ & & $(0.131)$ \\
\hline
\end{tabular}




\begin{tabular}{cccc}
\hline Constant & $\begin{array}{c}1.767 * * * \\
(0.163)\end{array}$ & $0.908 * *$ \\
& 0.378 & 0.491 & $(0.378)$ \\
\hline $\mathrm{R}^{2}$ & $259.072 * * *$ & $463.384 * * *$ & 0.478 \\
F-Statistic & & $390.534 * *$ \\
\hline
\end{tabular}

Nota. valores entre parênteses representam o erro padrão das variáveis; *, **, *** significância a 5\%, $1 \%$ e $0,1 \%$, respectivamente. Fonte: Elaborada pelos autores.

Os resultados da Tabela 6 mostram que o fluxo de caixa operacional, a rentabilidade do ativo, a alavancagem e o crescimento das vendas são variáveis estatisticamente significantes para a determinação da NCG. Entretanto, assim como para o modelo anterior, antes da realização de inferências realizou-se a análise dos testes de validação do modelo. Os resultados podem ser observados na Tabela 7.

Tabela 7

Resultados dos Testes de Validação

\begin{tabular}{l|ll}
\hline \multicolumn{1}{c|}{ Teste } & Estatística & p-valor \\
\hline VIF (maior valor) & 1.5049 & - \\
Shapiro-Wilk & 0.38948 & $0.0000^{*}$ \\
Breush-Pagan & 28764 & $0.0000^{*}$ \\
Hausman - Test & 57.491 & $0.0000^{*}$ \\
\hline
\end{tabular}

Nota. $*, * *, * * *$ significância a $5 \%, 1 \%$ e $<0,1 \%$, respectivamente.

Fonte: Elaborado pelos autores.

O teste VIF apontou ausência de multicolinearidade entre as variáveis explicativas do modelo. O teste de normalidade dos termos de erro (Shapiro-Wilk) levou, novamente, à rejeição da hipótese nula de normalidade, levando assim à conclusão de que os termos de erro do modelo não são normalmente distribuídos. O teste de Breush-Pagan também levou à rejeição da hipótese nula de homocedasticidade dos termos de erro, ou seja, os dados apresentam heterocedasticidade.

Dessa forma, assim como se procedeu para o modelo anterior, decidiu-se aplicar um modelo de regressão robusto à presença de heterocedasticidade. Assim, o modelo da equação 7 também foi estimado pelo método de mínimos quadrados generalizados factíveis, os resultados dessa estimação podem ser vistos na Tabela 8.

Tabela 8

Resultado do Modelo de Regressão por Mínimos Quadrados Generalizados Factíveis (MQG)

\begin{tabular}{ccc}
\hline & \multicolumn{2}{c}{ MQG } \\
\hline & CF & NCG \\
\cline { 2 - 3 } FCO & $-15.042^{* * *}$ & $0.526^{* * *}$ \\
ROA & $0.424^{* * *}$ & $0.007 * * *$ \\
LC & 0.128 & $-0.042^{* * *}$ \\
TAM & 0.714 & \\
TAM (2) & & $-0.019^{*}$ \\
ALAV & 1.884 & $-0.802^{* * *}$ \\
CRES & $0.169^{* * *}$ & $0.523^{* * *}$ \\
\hline Multiple $R$-squared & 0.8436 & 0.5656
\end{tabular}

Nota. valores entre parênteses representam o erro padrão das variáveis; *, **, *** significância a 5\%, $1 \%$ e $0,1 \%$, respectivamente. Fonte: Elaborada pelos autores

Conforme se observa na Tabela 8, o fluxo de caixa operacional, a rentabilidade do ativo e o crescimento das vendas foram variáveis estatisticamente significantes na determinação do ciclo 
financeiro das empresas. Enquanto, o fluxo de caixa operacional, a rentabilidade do ativo, a liquidez corrente, o tamanho, a alavancagem e o crescimento das vendas foram variáveis estatisticamente significantes na determinação da necessidade de capital de giro.

Esses resultados indicaram que empresas com maior fluxo de caixa operacional (FCO) tendem a ter um menor ciclo financeiro. $\mathrm{O}$ aumento do fluxo de caixa operacional pode ser derivado do aumento das vendas, o que provoca uma redução do ciclo econômico das empresas, ou seja, o prazo médio de estocagem tende a ser reduzido assim como o prazo médio de recebimento de clientes, o que, consequentemente, reduz o ciclo financeiro.

A relação positiva encontrada entre o FCO e a NCG corrobora o estudo de Hill, Kelly e Highfield (2010). De acordo com os autores, empresas com maiores fluxos de caixa operacional tendem a adotar uma gestão do capital de giro mais conservadora, com políticas de gestão de estoques e padrões de crédito menos restritivos, podendo assim aumentar a lucratividade.

Ao contrário do esperado e em desacordo com os apontamentos de Deloof (2003), a rentabilidade do ativo apresentou relação positiva com o ciclo financeiro e com a necessidade de capital de giro (NCG) das empresas, sinalizando que empresas mais rentáveis tendem a ter maior ciclo financeiro e NCG. A despeito disso, Nazir e Afza (2009) e Gill (2011) encontraram resultados semelhantes. De acordo com Gill (2011) a relação positiva entre rentabilidade e necessidade de capital de giro indicou que as empresas mais lucrativas, aparentemente, dedicam menor atenção à gestão eficiente do capital de giro.

A relação negativa encontrada para a liquidez corrente e a NCG indicou que empresas com maior liquidez tendem a ter uma menor necessidade de capital de giro. De forma geral, quanto maior a margem pela qual os ativos circulantes de uma empresa cobrem os passivos circulantes, maior a sua capacidade de honrar obrigações nos prazos estabelecidos. Dessa forma, quanto mais previsíveis as entradas de caixa, menor a necessidade de capital de giro líquido da empresa. Assim, quanto maior a liquidez corrente de uma empresa menor tende a ser a NCG.

No que se refere à variável tamanho, era esperada uma relação positiva com a NCG, conforme argumentam Chiou, Cheng e Wu (2006) e Kieschnick, Laplante e Moussawi (2006), Isto sinaliza que o aumento do tamanho da empresa pode levar a um aumento das atividades operacionais, e, por consequência, dos ativos e passivos circulantes. Entretanto, foi observada uma relação negativa entre NCG e tamanho. O que implica que empresas maiores tendem a ter uma menor necessidade de capital de giro. Hill, Kelly e Highfield (2010) argumentam que firmas menores tendem a acompanhar mais de perto as estratégias operacionais relacionadas à administração do capital de giro pois têm menos alternativas de financiamento disponíveis para bancar sua demanda por capital de giro. Apesar de não significantes, Palombini e Nakamura (2012) também encontraram resultados semelhantes para empresas brasileiras, embora considerados outro período de análise e espectro amostral.

Ademais, os resultados apontaram para uma relação significante e negativa da NCG com o endividamento, sinalizando que firmas mais alavancadas tendem a adotar uma política de gestão de capital de giro mais agressiva, para evitar novas emissões de títulos e ações. Os mesmos resultados foram obtidos por Chiou, Cheng e Wu (2006), Nazir e Afza (2008) na literatura internacional, e por Palombini e Nakamura (2012) na literatura nacional.

De acordo com Nazir e Afza (2009) empresas mais endividadas tendem a ter um maior cuidado em relação à gestão eficiente do capital de giro de forma a evitar que muito capital esteja vinculado às contas de curto prazo. Hill, Kelly e Highfield (2010) salientam que empresas em dificuldades gerenciam o capital mais agressivamente com políticas de capital de giro mais restritivas. Dessa forma essas empresas provavelmente vão reduzir o investimento em capital de giro operacional, cobrando recebíveis, restringindo as políticas de crédito a clientes, diminuindo o nível de estoques e aumentando o prazo de pagamento a fornecedores.

Por fim o crescimento das vendas (CRES) apresentou relação positiva com o ciclo financeiro e com a necessidade de capital de giro das empresas. Esse crescimento pode ser impulsionado pelo aumento da concessão de prazo a clientes, o que consequentemente, provocaria 
aumento no ciclo financeiro. Além disso, empresas com boas perspectivas de crescimento das vendas podem estar adotando uma política de capital de giro mais liberal visando aumento de vendas. A crise da economia brasileira poderia explicar em parte esta relação positiva, tendo em vista que em um ambiente de crise, visando aumentar suas vendas, as empresas tendem a adotar estratégias que resultem no aumento dos seus ativos e passivos operacionais.

\section{CONSIDERAÇÕES FINAIS}

A gestão do capital de giro é tema relevante na gestão das empresas, pois consome boa parte do tempo e do esforço dos gestores financeiros, uma vez que essa gestão demanda o estabelecimento e observância de políticas que definam o nível ótimo de cada componente, de maneira a assegurar o patamar de risco, de retorno, de liquidez e rentabilidade que contribua para a maximização do valor da empresa.

Entretanto, apesar da reconhecida relevância no âmbito das finanças corporativas, aparentemente é mais valorizada na perspectiva da práxis empresarial do que da área acadêmica, tendo em vista ser um tema pouco explorado em Finanças. Essa escassez de pesquisas sobre o tema capital de giro resulta: 1 . no baixo entendimento dos impactos da gestão inadequada sobre a rentabilidade; 2. no pouco conhecimento dos seus determinantes; e, 3 . na falta de evidências empíricas que associem o impacto do seu gerenciamento inadequado com a insolvência e a falência dos mais variados tipos e tamanhos de empresas.

Diante desse cenário, este estudo teve como objetivo identificar e analisar os possíveis determinantes da necessidade de capital de giro e do ciclo financeiro das empresas não financeiras de capital aberto brasileiras no período de 2010 a 2016. Para tal fim, foram realizadas análises de modelos para dados em painel além de modelagem de mínimos quadrados generalizáveis factíveis, com vistas a reduzir o efeito da heterocedasticidade da amostra, tornando os resultados mais robustos.

Os resultados mostraram que, a rentabilidade do ativo e o crescimento das vendas são variáveis estatisticamente significantes e positivamente relacionadas ao ciclo financeiro das empresas. Em contrapartida, o fluxo de caixa operacional apresentou relação negativa e estatisticamente significante com o ciclo financeiro das empresas. Ao contrário do esperado, empresas mais rentáveis tenderam a ter maiores ciclos financeiros.

Com relação aos determinantes da NCG, os resultados apontaram uma relação positiva para o fluxo de caixa operacional, a rentabilidade do ativo e o crescimento das vendas, enquanto por outro lado, apontaram uma relação negativa para a liquidez corrente, o tamanho e a alavancagem. Dessa forma, pode-se concluir que empresas maiores, com alta liquidez corrente e maior alavancagem tendem a apresentar menor necessidade de capital de giro. Esse resultado é consistente, visto que empresas maiores têm facilidade na obtenção de crédito para financiar suas necessidades de capital de giro, assim como a maior liquidez corrente indica a maior previsibilidade das entradas de caixa.

Ademais, este estudo não está isento de limitações visto que, os resultados podem ter sido afetados pela amostra de empresas estudadas, pelas variáveis escolhidas e pelo recorte temporal utilizado. Sugere-se para pesquisas futuras, a análise dos determinantes do capital de giro fazendo uma comparação entre as análises, tradicional e avançada do capital de giro. Além disso, pode-se tentar prever a eficácia da adição de variáveis da análise financeira de curto prazo em modelos de previsão de falência empresarial.

\section{AGRADECIMENTOS}

O presente trabalho foi realizado com apoio da Fundação de Amparo à Pesquisa do Estado de Minas Gerais (FAPEMIG) e da Coordenação de Aperfeiçoamento de Pessoal de Nível Superior Brasil (CAPES) - Código de Financiamento 001. 


\section{REFERÊNCIAS}

Afza T., Nazir, M. S. (2007). Is it better to be aggressive or conservative in managing working capital? Economic Review Conference (SERC), Singapore.

Araújo, V. S., \& Machado, M. A. V. (2007). Gestão do capital de giro de pequenas empresas. Revista Ciências Administrativas, 13(1), 49-61.

Archavli, E., Siriopoulos, K., Arvanitis, S. (2012). Determinants of working capital management. Working Paper SSRN (http://ssrn.com/abstract=2179907).

Assaf Neto, A., \& Lima, F. G. (2009). Curso de administração financeira. Atlas.

Assaf Neto, A, Silva, C. A. T. (2009). Administração de capital de giro. Atlas.

Azeem, M. M., \& Marsap, A. (2015). Determinant factors and working capital requirement. International Journal of Economics and Finance, 7(2), 280-292.

Baños-Caballero, S., García-Teruel, P. J., \& Martínez-Solano, P. (2014). Working capital management, corporate performance, and financial constraints. Journal of Business Research, 67(3), 332-338.

Berk, J., \& DeMarzo, P. (2009). Finanças empresariais. Bookman Editora.

Chang, C. C. (2018). Cash conversion cycle and corporate performance: Global evidence. International Review of Economics \& Finance, 56, 568-581.

Chiou, J. R., Cheng, L., \& Wu, H. W. (2006). The determinants of working capital management, The Journal of American Academy of Business, 10(1), 149-155.

Deloof, M. (2003). Does working capital management affect profitability of Belgian firms? Journal of Business Finance \& Accounting, 30(3-4), 573-588.

Eljelly, A. M. (2004). Liquidity-profitability tradeoff: an empirical investigation in an emerging market. International Journal of Commerce and Management, 14(2), 48-61.

Fusco, J. P. A. (1996). Necessidade do capital de giro e nível de vendas. Revista de Administração de Empresas, 36(2), 53-66.

Ganesan, V. (2007). An analysis of working capital management efficiency in telecommunication equipment industry. Rivier Academic Journal, 3(2), 1-10.

Garcia-Teruel, P. J.; Martinez-Solano, P. M. (2007). Effects of working capital management on SME profitability. International Journal of Management Finance, 3(2), 164-177.

Gentry, J. A. (1988). State of the art of short-run financial management. Financial Management, 41-57.

Gill, A. (2011). Factors that influence working capital requirements in Canada. Economics and Finance Review, 1(3), 30-40. 
Guimarães, A., \& Nossa, V. (2010). Capital de giro, lucratividade, liquidez e solvência em operadoras de planos de saúde. BBR-Brazilian Business Review, Vitória, 7(2), 40-63.

Hill, M. D., Kelly, G. W., \& Highfield, M. J. (2010). Net operating working capital behavior: a first look. Financial Management, 39(2), 783-805.

Jalal, A., \& Khaksari, S. (2019). Cash cycle: A cross-country analysis. Financial Management. https://doi.org/10.1111/fima.12273

Kargar, J., \& Blumenthal, R. A. (1994). Leverage impact on working capital in small businesses. TMA Journal, 14(6), 46-53.

Kieschnick, R., Laplante, M., \& Moussawi, R. (2006). Corporate working capital management: determinants and consequences. [Working Paper], The Wharton School at the University of Pennsylvania, Filadélfia, Pensilvânia.

Lamberson, M. (1995). Changes in working capital of small firms in relation to changes in economic activity. American Journal of Business, 10(2), 45-50.

Nazir, M. S., \& Afza, T. (2008). On the factor determining working capital requirements. Proceedings of ASBBS, 15(1), 293-301.

Nazir, M. S., \& Afza, T. (2009). Working capital requirements and the determining factors in Pakistan. IUP Journal of Applied Finance, 15(4), 28.

Palombini, N. V. N., \& Nakamura, W. T. (2012). Key factors in working capital management in the Brazilian market. Revista de Administração de Empresas, 52(1), 55-69.

Seidel, A., \& Kume, R. (2003). Contabilização das variações da necessidade de capital de giro. Revista Contabilidade \& Finanças, 14(31), 66-77.

Silva, J. O., Santos, V., Hein, N., \& Lyra, R. L. W. C. (2012). Nível informacional entre a análise tradicional e avançada do capital de giro. Revista Pretexto, 13(2), 40-56.

Shin, H. H., \& Soenen, L. A. (1998). Efficiency of working capital management and corporate profitability. Financial Practice \& Education, 8(2), 37-51.

Singh, H. P., \& Kumar, S. (2014). Working capital management: a literature review and research agenda. Qualitative Research in Financial Markets, 6(2), 173-197.

Smith, K. V. (1973). State of the art of working capital management. Financial Management, 5055.

Wasiuzzaman, S., \& Arumugam, V. C. (2013). Determinants of working capital investment: A study of Malaysian public listed firms. Australasian Accounting Business \& Finance Journal, 7(2), 49-70. 